\title{
Efficacy of combined use of Xuebijing and ulinastatin for paraquat poisoning: A systematic review and meta- analysis of randomized controlled trials
}

yuqiong xu ( $\square$ xuyuqiong@126.com )

Southern University of science and Technology Hospital

Xiaoyan Ding

Bao'an People's Hospital,Shenzhen

Rui Li

Shenzhen University General Hospital

Xiang Long

Peking University ShenZhen Hospital

Wendi Huang

Peking University ShenZhen Hospital

Jiezhu Ding

Peking University ShenZhen Hospital

Yuqiong Xu

Southern University of science and Technology Hospital

\section{Research article}

Keywords: Xuebijing, Ulinastatin, Paraquat poisoning, Effectiveness, Systematic review, Meta-analysis

Posted Date: September 13th, 2021

DOl: https://doi.org/10.21203/rs.3.rs-900448/v1

License: (c) (7) This work is licensed under a Creative Commons Attribution 4.0 International License. Read Full License 


\section{Abstract}

Background: There are no clinically effective antidotes for paraquat poisoning, which progresses rapidly with a poor prognosis and high mortality. The addition of Xuebijing (XBJ) and ulinastatin (UTI) combination to conventional therapy has been reported as a novel treatment approach.

Objective: To compare the effectiveness of Xuebijing combined with ulinastatin and conventional treatment group in the treatment of paraquat poisoning.

Methods: The CNKI, VIP, WanFang, PubMed, EMBASE, and MEDLINE databases were searched for publications on randomized controlled clinical trials that compared the $\mathrm{XBJ}+\mathrm{UTI}$ combination as an additional treatment to conventional therapy versus conventional therapy alone.

Results: Quality assessment of the selected publications was performed and data were extracted for analysis. The final analysis included five publications, reporting 588 patients with paraquat poisoning. The control and XBJ+UTI groups comprised 294 patients each; 138 and 100 patients in the control and conventional therapy plus XBJ+UTI groups died, respectively. The combined analysis showed that the mortality relative risk (RR) was 0.72 and $\mathrm{I}^{2}$ was $46.2 \%$. Three publications reported of pulmonary fibrosis (PF) and multiple organ dysfunction syndrome (MODS), in which 134 patients were included in each of the control and XBJ+UTI groups. MODS occurred in 117 and 88 patients in the control and conventional therapy plus XBJ+UTI groups, respectively. The combined analysis using the random-effects model showed that the RR was 0.75 and $\mathrm{I}^{2}$ was $0.0 \%$. PF occurred in 99 and 68 patients in the control and conventional therapy plus XBJ+UTI groups, respectively. The combined analysis using the random-effects model showed that the RR was 0.69 and $\mathrm{I}^{2}$ was $0.0 \%$.

Conclusions: We preliminarily demonstrated that compared with those of conventional therapy alone, the addition of XBJ+UTI combination for the treatment of paraquat poisoning could reduce the mortality rate and incidence of MODS and PF.

\section{Background}

Paraquat is a bipyridine herbicide. Acute paraquat poisoning is commonly encountered in emergency departments in China. Most patients with paraquat poisoning have a poor prognosis and the associated mortality rate is approximately $25-76 \%[1]$, with severe cases exhibiting a mortality rate of up to $100 \%[2]$. If accidentally ingested by humans, paraquat may enter the bloodstream in $5-15 \%$ of the cases [3] and rapidly accumulate in the lung tissues[ $[4,5]$. The initial stage of poisoning can lead to acute lung injury/acute respiratory distress syndrome, and the later stages of poisoning can cause pulmonary fibrosis (PF) and multiple organ dysfunction syndrome (MODS). Although the pathogenesis of paraquat poisoning has not been fully elucidated, studies have demonstrated that paraquat can induce the release of various inflammatory factors and mediators in the human body. It also activates cells to release various types of cytotoxic substances, such as proteases, phospholipases, and oxygen free radicals, thereby damaging tissues and cells. Therefore, while the early treatment aims to prevent paraquat from further entering the blood and to remove paraquat that has entered the blood, more critically, it should improve the resistance of cells and tissues to the toxicity of paraquat that has already entered the blood[6] . 
Current conventional therapies include gastric lavage, catharsis, kaolin/activated carbon adsorption, fluid replacement, diuresis, hormone therapy, and blood purification[7-9]. There is a lack of clinically effective antidotes. Both Xuebijing (XBJ) and ulinastatin (UTI) can inhibit lysosomal enzyme release, stabilize cell membranes, scavenge oxygen free radicals, and protect vascular endothelial cells. These effects help prevent inflammation, improve tissue microcirculation and perfusion, and reduce cell and tissue damages. In addition, XBJ and UTI can act synergistically. There has been growing number of reports on the addition of XBJ + UTI combination to conventional therapy as a novel treatment approach for paraquat poisoning. The objective of the present study was to conduct a systematic review and meta-analysis on the addition of XBJ + UTI combination to conventional therapy for paraquat poisoning, with the aim to provide a basis for evidence-based medicine for paraquat poisoning.

\section{Materials And Methods Search strategy}

The China National Knowledge Infrastructure (CNKI), Weipu Journal Database (VIP), Wanfang, PubMed, EMBASE, and MEDLINE databases were searched for publications on randomized controlled clinical trials (RCCTs) on paraquat poisoning. The date of coverage was from the date the database was built to August 5 , 2021. Details of the search strategy for each database are shown in Supplementary. Search Strategy-1.

\section{Inclusion criteria}

The following were the inclusion criteria. The study was conducted according to the PICOS principles[10]; P: patients with paraquat poisoning; l: therapies for control group included gastric lavage, catharsis, white clay/activated carbon adsorption, fluid replacement, hormone therapy, diuresis, and blood purification and therapies for the treatment group were based on the therapies received by the control group, with the addition of XBJ and UTI injections; C: comparison between the XBJ + UTI and control groups; O: outcome parameters included at least one of the following: mortality rate, MODS incidence rate, and PF incidence rate; S: RCCT.

\section{Exclusion criteria}

The following were used as the inclusion criteria. Animals as study subjects; interventions did not include the use of XBJ + UTI; nonrandomized controlled trials, retrospective studies, and case reports; outcome parameters did not include at least one of the following: mortality rate, MODS incidence rate, and PF incidence rate.

\section{Quality assessment}

The Cochrane Collaboration's risk-of-bias tool was employed to assess the included publications[11]. Using the domain-based evaluation method, the publications were evaluated with respect to the generation of sequence, concealment of allocation, blinding of participants, study personnel, and outcome assessors; incomplete outcome data; selective outcome reporting; and other sources of bias.

\section{Data extraction}

The publications were carefully reviewed by two researchers. The characteristics of the study populations including age, sex, treatment course, usage, and primary and secondary outcomes were extracted from the 
publications. The results were cross-validated and discordant results were resolved by discussion with a third researcher.

\section{Statistical analysis}

Data analysis was performed using Stata 15.1 (Stata Corp, College Station, TX) professional software. Relative risk (RR) and its 95\% confidence interval $(\mathrm{Cl})$ were used as the statistical parameters for data concerning two categorical variables. Continuous variables are expressed as MD and 95\% $\mathrm{Cl}$. According to the Cochrane Handbook, heterogeneity between studies was described using $\mathrm{I}^{2}$. When the $\mathrm{I}^{2}$ was 0 , it was considered that no heterogeneity existed between studies; when $\mathrm{I}^{2}$ was between $0-50 \%$, there was mild heterogeneity, and a fixedeffects model or random-effects model was used; and when $\mathrm{I}^{2}$ was $>50 \%$, the heterogeneity between studies was substantial, and a sensitivity analysis, subgroup analysis, or meta-regression was used to find the source of heterogeneity. If the source of heterogeneity could not be identified, Mantel-Haenszel (M-H) random effects model was used.

\section{Results}

The number of publications retrieved from the CNKI, VIP, Wanfang, PubMed, EMBASE, and MEDLINE databases was 101. Seventy-one publications were obtained after removing duplications. Based on the abstract review, 2 case reports, 3 reviews on treatment of paraquat poisoning, 37 animal studies, and 6 retrospective studies were excluded. Subsequently, the full text was reviewed and 2 studies on UTI vs. XBJ + UTI and 2 studies without relevant outcome parameters and with duplicated data were excluded. Finally, five publications[12-16]on RCCTs were obtained, as shown in Fig. 1. The five publications were assessed using the recommendations in the Cochrane Handbook for Systematic Reviews of Interventions for evaluating original RCTs. The assessment included the following: random sequence generation;allocation concealment; blinding of participants, study personnel, and outcome assessors; incomplete outcome data; selective outcome reporting; and other potential bias that could threaten authenticity. For each study data, these seven criteria were determined as "yes" (low risk), "no" (high risk), or "unclear" (lack of relevant data or uncertain conditions). The assessment results are shown in Fig. 2. The baseline characteristics and data were extracted from the five publications, one of which did not describe the treatment course of XBJ + UTI. The results are shown in Table 1. 
Table 1

Characteristics of the included studies

\begin{tabular}{|c|c|c|c|c|c|c|c|c|c|c|}
\hline Study & Year & DC & Group & Case & Age & $M / F$ & $\begin{array}{l}\mathrm{PQ} \\
\text { dose } \\
\text { (ml) }\end{array}$ & $\begin{array}{l}\text { Interval } \\
\text { time(min) }\end{array}$ & Interventions & Outcome \\
\hline \multirow[t]{2}{*}{$\begin{array}{l}\text { Zhao } \\
\text { et al. } \\
\text { [12] }\end{array}$} & \multirow[t]{2}{*}{2014} & \multirow[t]{2}{*}{ प } & $\begin{array}{l}\mathrm{TG} \\
\mathrm{CG}\end{array}$ & $\begin{array}{l}43 \\
43\end{array}$ & \multirow[t]{2}{*}{$\begin{array}{l}41.84 \\
\pm 6.96 \\
40.05 \\
\pm \\
11.34\end{array}$} & $\begin{array}{l}19 / 24 \\
17 / 26\end{array}$ & \multirow[t]{2}{*}{$\begin{array}{l}10- \\
90\end{array}$} & \multirow[t]{2}{*}{$20-240$} & \multirow[t]{2}{*}{$\begin{array}{l}\text { TG:(XBJ } \\
50 \mathrm{ml} \text { bid + } \\
\text { UTI 20wu } \\
\text { bid)*10d + } \\
\text { CT }\end{array}$} & \multirow[t]{2}{*}{$\begin{array}{l}\text { Mortality } \\
\text { MODS } \\
\text { PF }\end{array}$} \\
\hline & & & & & & & & & & \\
\hline \multirow{2}{*}{$\begin{array}{l}\text { Tu et } \\
\text { al. } \\
\text { [13] }\end{array}$} & \multirow[t]{2}{*}{2016} & \multirow[t]{2}{*}{ प } & TG & 45 & \multirow{2}{*}{$\begin{array}{l}41.85 \\
\pm 6.98 \\
40.08 \\
\pm \\
11.35\end{array}$} & $20 / 25$ & \multirow{2}{*}{$\begin{array}{l}10- \\
90\end{array}$} & \multirow[t]{2}{*}{$20-240$} & \multirow{2}{*}{$\begin{array}{l}\text { TG: (XBJ } \\
50 \mathrm{ml} \text { bid + } \\
\text { UTI 20wu } \\
\text { bid)*10d + } \\
\text { CT } \\
\text { CG: CT }\end{array}$} & \multirow{2}{*}{$\begin{array}{l}\text { Mortality } \\
\text { पMODS } \\
\text { PF }\end{array}$} \\
\hline & & & IG & 45 & & $15 / 30$ & & & & \\
\hline \multirow{3}{*}{$\begin{array}{l}\text { Xia et } \\
\text { al. } \\
{[14]}\end{array}$} & \multirow[t]{3}{*}{2017} & \multirow[t]{3}{*}{ प } & TG & 40 & \multirow{3}{*}{$\begin{array}{l}34.9 \\
\pm 6.8 \\
\\
35.5 \\
\pm 7.5\end{array}$} & $17 / 23$ & \multirow[t]{3}{*}{ NA } & \multirow[t]{3}{*}{ NA } & \multirow{3}{*}{$\begin{array}{l}\text { TG: } \\
\text { (XBJ100ml } \\
\text { bid-qid + UTI } \\
1 \text { wu qd- } \\
\text { tid)*d + CT } \\
\text { CG: CT }\end{array}$} & \multirow{3}{*}{$\begin{array}{l}\text { Mortality } \square \\
\mathrm{PaCO}_{2} \square \\
\mathrm{PaO}_{2^{-}}\end{array}$} \\
\hline & & & CG & 40 & & $22 / 18$ & & & & \\
\hline & & & & & & & & & & \\
\hline \multirow{2}{*}{$\begin{array}{l}\text { Su et } \\
\text { al. } \\
\text { [15] }\end{array}$} & \multirow[t]{2}{*}{2018} & \multirow[t]{2}{*}{ प } & TG & 120 & $\begin{array}{l}41.90 \\
\pm 10.2\end{array}$ & $46 / 74$ & $\begin{array}{l}16- \\
89\end{array}$ & $\begin{array}{l}41.20 \pm \\
20.15\end{array}$ & $\begin{array}{l}\text { TG: (XBJ } \\
50 \mathrm{ml} \mathrm{bid} \mathrm{+} \\
\text { UTI } 20 \mathrm{wu} \\
\text { bid)*3d +CT }\end{array}$ & \multirow{2}{*}{$\begin{array}{l}\text { Mortality } \\
\mathrm{PaCO}_{2} \square \\
\mathrm{PaO}_{2} \square \\
\text { APACHE } \\
\text { II scores } \square \\
\text { SOD! } \\
\text { MDA }\end{array}$} \\
\hline & & & CG & 120 & $\begin{array}{l}40.80 \\
\pm \\
10.32\end{array}$ & $45 / 75$ & $\begin{array}{l}15- \\
90\end{array}$ & $\begin{array}{l}40.50 \pm \\
20.12\end{array}$ & $\begin{array}{l}\text { bid)*3d + CT } \\
\text { CG: CT }\end{array}$ & \\
\hline
\end{tabular}

邓:Not mentioned; $邓:$ Expert consensus on diagnosis and treatment of acute paraquat poisoning; PQ: Paraquat; NM: Not mentioned; TG: Treatment group; CG: Control group; CT: Control treatment; M/F: Male/Female; XBJ: Xuebijing injection; UTI: Ulinastatin injection; DC: Diagnostic criteria; MODS: Multiple organ dysfunction

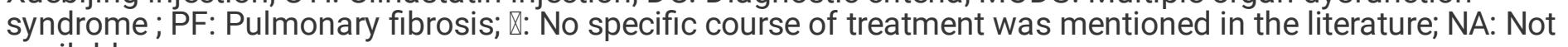
available. 


\begin{tabular}{|c|c|c|c|c|c|c|c|c|c|c|}
\hline Study & Year & DC & Group & Case & Age & M/F & $\begin{array}{l}\text { PQ } \\
\text { dose } \\
(\mathrm{ml})\end{array}$ & $\begin{array}{l}\text { Interval } \\
\text { time(min) }\end{array}$ & Interventions & Outcome \\
\hline \multirow{3}{*}{$\begin{array}{l}\text { Mu et } \\
\text { al. } \\
\text { [16] }\end{array}$} & \multirow[t]{3}{*}{2018} & \multirow[t]{3}{*}{ 口 } & $\mathrm{TG}$ & & \multirow{3}{*}{$\begin{array}{l}41.16 \\
\pm 7.28 \\
42.36 \\
\pm 7.21\end{array}$} & & \multirow[t]{3}{*}{ NA } & \multirow[t]{3}{*}{ NA } & \multirow{3}{*}{$\begin{array}{l}\text { TG: (XBJ } \\
50 \mathrm{ml} \mathrm{bid} \mathrm{+} \\
\text { UTI } 20 \mathrm{wu} \\
\text { bid) }{ }^{\star} 10 \mathrm{~d}+ \\
\text { CT }\end{array}$} & \multirow{3}{*}{$\begin{array}{l}\text { Mortality } \\
\mathrm{MODS} \square \\
\mathrm{PF} \square \\
\mathrm{PaCO}_{2} \square \\
\mathrm{PaO}_{2}\end{array}$} \\
\hline & & & CG & 46 & & \multirow{2}{*}{$21 / 25$} & & & & \\
\hline & & & & & & & & & & \\
\hline \multicolumn{11}{|c|}{ 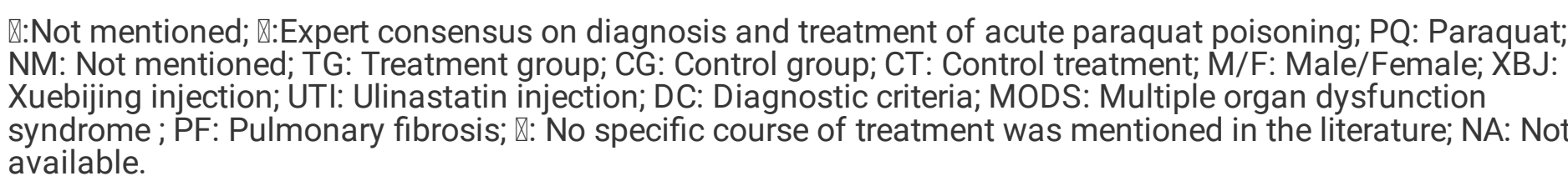 } \\
\hline
\end{tabular}

\section{Sensitivity analysis}

The meta-analysis on mortality rate revealed that the total heterogeneity $\mathrm{I}^{2}$ between the studies was $46.2 \%(P=$ 0.115). The random effect model for $\mathrm{M}-\mathrm{H}$ heterogeneity showed that the RR was 0.72 (95\% $\mathrm{Cl}: 0.55-0.94)$. The forest plot showed that the RR value and its $\mathrm{Cl}$ of Xia's study were significantly different from those of the other four studies in Fig. 3. Hence, that study was excluded and a meta-analysis was conducted again. The results showed that the total heterogeneity $\mathrm{I}^{2}$ between the studies was $0.2 \%(P=0.391)$ and fixed-effects model showed that the RR was 0.79 (95\% Cl: 0.66-0.94) (Fig. 4). The RR value and $95 \% \mathrm{Cl}$ after excluding the study of Xia (2017) were not significantly altered, indicating that the results of the meta-analysis on mortality rate were highly robust.

\section{Mortality rate}

Five publications reported the mortality rate in the control and experimental groups. A total of 588 patients with paraquat poisoning were included, with 294 patients each in the control and XBJ + UTI groups. One hundred and thirty-eight patients in the control group and 100 patients in the XBJ + UTI group died. Combined with the sensitivity analysis results described above and using the random effect model for $\mathrm{M}-\mathrm{H}$ heterogeneity, the results showed that the RR was 0.79 (95\% Cl: 0.66-0.94) (Fig. 4).

\section{Multiple organ dysfunction syndrome}

Three publications reported the incidence of MODS. A total of 268 patients were included, with the control and experimental groups comprising 134 patients each. MODS occurred in 117 patients in the control group and 88 patients in the XBJ + UTI group. The combined analysis using the random-effects model showed that the RR was 0.75 (95\% Cl: $0.65-0.86)$ and $\mathrm{I}^{2}$ was $0.0 \%(P=0.901)$ (Fig. 5).

\section{Pulmonary fibrosis}

Three studies reported the incidence of PF. Both the control and experimental groups comprised 134 patients. PF occurred in 99 patients in the control group and 68 in the XBJ + UTI group. The combined analysis using the 
random-effects model showed that the RR was $0.69(95 \% \mathrm{Cl}: 0.57-0.83)$ and $\mathrm{I}^{2}$ was $0.0 \%(\mathrm{P}=0.992)(\mathrm{Fig} .6)$.

\section{Publication bias}

Relevant research indicates that tests for funnel plot asymmetry are not necessary when there are less than 10 publications included and when the standard errors of the intervention effects of the included publications are similar[17-20]. The present study included five publications; therefore, funnel plots were not drawn to evaluate publication bias.

\section{Discussion}

Our meta-analysis showed that the combination of XBJ and UTI exhibited good efficacy for the treatment of acute paraquat poisoning. Compared with those of the control group, XBJ + UTI could significantly reduce mortality and the occurrence of MODS and PF in patients.In China, the early use of XBJ and UTI combination was often for the treatment of patients with sepsis, and the combination presented good efficacy[21, 22]. There is an increasing number of reports on the addition of XBJ and UTI combination to conventional therapy as a novel treatment approach for acute paraquat poisoning. In terms of improving the mortality of paraquat poisoning, although three literatures[12, 13, 16] showed that XBJ + UTI group had no significant difference in reducing the mortality of paraquat poisoning compared with the control group, two literatures[14, 15] showed that XBJ + UTI group could reduce the mortality of paraquat poisoning compared with the control group, and the difference between the two groups was statistically significant. Finally, the meta-analysis of 5 articles and the expansion of sample size showed that XBJ + UTI group could reduce the mortality of paraquat poisoning compared with the control group, and the difference between the two groups was statistically significant.

Like artemisinin used for malaria treatment, XBJ used as an injection is also a medicinal ingredient extracted from a traditional Chinese medicine. Its main components include hydroxysafflor yellow A, ligustrazine, salvianic acid $A$, ferulic acid, paeoniflorin, and protocatechuic aldehyde[23]. XBJ can effectively improve the prognosis of patients with paraquat poisoning, and the potential mechanisms include the following. First, by inhibiting the overexpression of proinflammatory factors, such as tumor necrosis factor a (TNF-a), platelet-derived growth factor (PDGF), insulin-like growth factor-1 (IGF-1), transforming growth factor- $\beta 1$ (TGF- $\beta 1$ ), interleukin (IL)- 1 , and

IL-6; blocking the TGF- $\beta 1 /$ ERK signaling pathway[24]; promoting the expression of anti-inflammatory factors, such as IL-10; re-establishing the balance of inflammatory/anti-inflammatory transmitters; attenuating inflammation; and exerting organ protection. Second, by modulating a part of amino acids and fatty acids, and energy metabolism to resist the toxicity of paraquat[25].Third, by regulating the p38 MAPK/NF-KB pathway to reduce the degree of inflammatory response to paraquat poisoning[26].Fourth, by improving the free radicalscavenging activity of superoxide dismutase (SOD) in the body[27], thereby reducing oxidative damage caused by the excessive release of free radicals. This protects the vascular endothelium, lowers vascular permeability,and inhibits extracellular matrix depositions.Fifth,by antagonizing endotoxin,reducing endotoxininduced monocyte/macrophage activation, and releasing inflammatory mediators that may lead to fever, leukemoid reaction, shock, and other symptoms associated with sepsis, thereby improving prognosis[28]. Sixth, by regulating the number of T-cell subsets and enhancing the cellular immunity of the body[29]. Finally, by inducing the increase in platelet count and fibrin content, antagonizing the internal and external coagulation pathways, promoting the activation of fibrinolysis system, and ameliorating coagulation abnormalities[30]. 
UTI used as an injection is a glycoprotein originally extracted from fresh human urine, and it can inhibit the activities of various proteases. Like XBJ, UTI can inhibit the excessive release of inflammatory mediators, stabilize cell membrane structures, participate in inflammatory response regulation, and inhibit oxygen free radical and superoxide production[31-35]. It can also downregulate the expression of TGF- $\beta 1$, TNF- $a$, and nuclear factor KB (NF-KB) [36] and reduce the levels of NSE and COX-2[37], thereby protecting the organs of patients. Relevant research has confirmed that the addition of XBJ and UTI combination to conventional therapy can exert a synergistic effect and enhance treatment efficacy.

Although the present study has demonstrated the efficacy of XBJ and UTI combination for the treatment of paraquat poisoning, it is worth noting that the results of this study require further careful examination due to the quality of the included publications. First, the number of publications included was relatively small, and most of them reported single-center studies with small sample sizes. With the exception of the study of Su (2018)[16], which included 120 patients in each of the control and experimental groups, the remaining four publications had smaller sample sizes. Second, no publication has specified the time points of the outcome parameters. Fourth, the prognosis of patients with paraquat poisoning is related to poison doses, time from poisoning to hospitalization, patient's age, and baseline health condition. Three publications reported the poison doses and time from poisoning to hospital admission, and no publication reported whether patients had baseline diseases. Third, all patients included in the study were Chinese, and whether the benefits would be observed in other races were unclear and remain to be elucidated in future studies.

\section{Conclusions}

Our study preliminarily demonstrated that compared with those of conventional therapy alone, the addition of $\mathrm{XBJ}+\mathrm{UTI}$ combination for the treatment of paraquat poisoning could reduce mortality rate of patients and the incidence of MODS and PF. Nonetheless, further evidence from high-quality, multicenter, randomized clinical trials with large sample sizes is needed.

\section{References}

1. Yu H, Fang Q. Clinical data analysis of severe acute paraquat poisoning. Chinese Journal of Industrial Hygiene Occupational Diseases. 2010;28(10):786-7. (article in chinese).

2. Liu X, Jing Z, Zhang W, Sun H. Treatment of paraquat poison treatment and analysis of relevant factors. Journal of Jilin Medical College. 2008;29(3):127-9. (article in chinese).

3. Gao Q, Shi Z. Advances in clinical research on acute paraquat poisoning. Medical review. 2010;16(05):7103.

4. Manchester LC, Coto-Montes A, Boga JA, Andersen LP, Zhou Z, Galano A, Vriend J, Tan DX, Reiter RJ. Melatonin: An ancient molecule that makes oxygen metabolically tolerable. J Pineal Res. 2015;59(4):40319.

5. Zhang C, Liao H, Lei C. Pathogenesis and treatment of paraquat poisoning. Chinese Journal of Industrial Medicine. 2018;31(02):96-8. (article in chinese).

6. Lin JL, Lin-Tan DT, Chen KH, Huang WH. Repeated pulse of methylprednisolone and cyclophosphamide with continuous dexamethasone therapy for patients with severe paraquat poisoning. Crit Care Med.

2006;34(2):368-73. 
7. Wang Y, Wu Y, Shen F, Liu B, Qian H, Yang H, Cheng Y, Liu M. [Clinical effect of haemoperfusion combined with continuous veno-veno haemofiltration in treatment of paraquat poisoning: A Meta-analysis]. Zhonghua Wei Zhong Bing Ji Jiu Yi Xue. 2019;31(2):214-20. (article in chinese).

8. Lan C, Lyu Q, Pei H, Meng X, Liu Q, Jia X, Li Z, Wang C, Ye H, Fan Y. [Effect of hemoperfusion combined with continuous veno-venous hemofiltration on acute paraquat poisoning: A Meta-analysis]. Zhonghua Wei Zhong Bing Ji Jiu Yi Xue. 2018;30(8):783-9. (article in chinese).

9. Li C, Hu D, Xue W, Li X, Wang Z, Ai Z, Song Y, Liu X, Cheng J, Fan S, Zhao L, Wang L, Mohan C, Peng A. Treatment outcome of combined continuous venovenous hemofiltration and hemoperfusion in acute paraquat poisoning: A prospective controlled trial. Crit Care Med. 2018;46(1):100-7.

10. Higgins J, Green S. Cochrane Handbook for Systematic Reviews of Interventions, Version 5.1.0., 2013. Available from: http://www. cochrane-handbook.org.

11. Higgins JP, Altman DG, Gotzsche PC, Juni P, Moher D, Oxman AD, Savovic J, Schulz KF, Weeks L, Sterne JA. The Cochrane Collaboration's tool for assessing risk of bias in randomised trials. BMJ. 2011;343:d5928.

12. Zhao Y, Cheng W, Hao Y. Clinical study of ulinastatin combined with Xuebijing injection in the treatment of acute paraquat poisoning. China Practical Medicine. 2014;9(17):10-1. (article in chinese).

13. Tu S, Zhang Y. the efficacy of Xuebijing injection combined with ulinastatin in the treatment of acute paraquat poisoning. Evaluation Analysis of Drug-Use in Hospitals of China. 2016;16(07):931-3. (article in chinese).

14. Xia Y. Efficacy of ulinastatin combined with Xuebijing injection in the treatment of acute paraquat poisoning. Home Medicine. 2017; (1): 59-60. (article in chinese).

15. Mu Y. Effect of ulinastatin combined with Xuebijing on arterial blood gas index and incidence of multiple organ dysfunction syndrome in patients with acute paraquat poisoning. Medical Science Abroad (Medical Geography Branch). 2018;39(02):159-61. (article in chinese).

16. Su Z, Zhen L, Zhong C. Effect of xuebijing injection and ulinastatin combined with hemoperfusion on arterial blood gas index in patients with acute paraquat poisoning. China Journal of Pharmaceutical Economics. 2018;13(08):101-3. (article in chinese).

17. Peters JL, Sutton AJ, Jones DR, Abrams KR, Rushton L. Comparison of two methods to detect publication bias in meta-analysis. JAMA. 2006;295(6):676-80.

18. Harbord RM, Egger M, Sterne JA. A modified test for small-study effects in meta-analyses of controlled trials with binary endpoints. Stat Med. 2006;25(20):3443-57.

19. Sterne JA, Egger M. Funnel plots for detecting bias in meta-analysis: Guidelines on choice of axis. J Clin Epidemiol. 2001;54(10):1046-55.

20. Sterne JA, Egger M, Smith GD. Systematic reviews in health care: Investigating and dealing with publication and other biases in meta-analysis. BMJ. 2001;323(7304):101-5.

21. Xu YQ, Geng Y, Tong HS, Li HB, Wan P, Su L. Meta-analysis of xuebijing injection in improving survival rate of patients with sepsis. Clinical Journal of Traditional Chinese Medicine. 2014;26(05):456-60. (article in chinese).

22. Chen G, Gao Y, Jiang Y, Yang F, Li S, Tan D, Ma Q. Efficacy and safety of xuebijing injection combined with ulinastatin as adjunctive therapy on sepsis: A systematic review and Meta-Analysis. Front Pharmacol. 2018;9:743. 
23. Zuo L, Sun Z, Wang Z, Ding D, Xu T, Liu L, Gao L, Du S, Kang J, Zhang X. Tissue distribution profiles of multiple major bioactive components in rats after intravenous administration of Xuebijing injection by UHPLC-Q-Orbitrap HRMS. Biomed Chromatogr. 2019;33(2):e4400.

24. Li H, Wang X. Study on the protective effect of Xuebijing injection on lung injury in rats with acute paraquat poisoning. Modern Journal of Integrated Traditional Chinese Western Medicine. 2019;28(14):1508-13. (article in chinese).

25. Li S, Zhu Y, Liu W, Wu Y, Jiang F, Yan X. A Gas Chromatography-Mass Spectrometry Based Metabolomics Study on the Therapeutic Effects of Xuebijing Injection on Paraquat Poisoning Rats. Journal of Analytical Science. 2019;35(3):289-94. (article in chinese).

26. Liu MW, Liu R, Wu HY, Zhang W, Xia J, Dong MN, Yu W, Wang Q, Xie FM, Wang R, Huang YQ, Qian CY. Protective effect of Xuebijing injection on D-galactosamine- and lipopolysaccharide-induced acute liver injury in rats through the regulation of p38 MAPK, MMP-9 and HO-1 expression by increasing TIPE2 expression. Int J Mol Med. 2016;38(5):1419-32.

27. Hu HX, Zhu MQ, Sun YC, Ma C, Wang X, Liu XL. Xuebijing enhances neuroprotective effects of ulinastatin on transient cerebral ischemia via Nrf2-are signal pathways in the hippocampus. J Biol Regul Homeost Agents. 2018;32(5):1143-9.

28. Wang L, Liu Z, Dong Z, Pan J, Ma X. Effects of Xuebijing injection on microcirculation in septic shock. J Surg Res. 2016;202(1):147-54.

29. Chen X, Feng Y, Shen X, Pan G, Fan G, Gao X, Han J, Zhu Y. Anti-sepsis protection of Xuebijing injection is mediated by differential regulation of pro- and anti-inflammatory Th17 and T regulatory cells in a murine model of polymicrobial sepsis. J Ethnopharmacol. 2018;211:358-65.

30. Li N, Jiang LW, Yu L. Systematic review of Xuebijing injection for the treatment of sepsis. Chinese Journal of Modern Drug Application. 2013.(article in chinese).

31. Song Z, Chen G, Lin G, Jia C, Cao J, Ao G. The ultra-early protective effect of ulinastatin on rabbit acute lung injury induced by paraquat. BMC Emerg Med. 2013;13(Suppl 1):7.

32. He G, Li Q, Li W, Ruan Y, Xiong X, Song X, Zeng F. Effect of ulinastatin on interleukins and pulmonary function in bypass patients: A meta-analysis of randomized controlled trials. Herz. 2020;45(4):335-46.

33. Ling L, Li Y, Li H, Li W, Zhang HB. MMP-2 and MMP-9 gene polymorphisms act as biological indicators for ulinastatin efficacy in patients with severe acute pancreatitis. Medicine. 2019;98(24):e15831.

34. Xiong L, Sun L, Liu S, Zhu X, Teng Z, Yan J. The protective roles of urinary trypsin inhibitor in brain injury following fat embolism syndrome in a rat model. Cell Transplant. 2019;28(6):704-12.

35. Xu HY, Rong XS, Wang DP, Jiang SY, Zang ZD, Xia W, Zhang F, Yan J. Effect of urinary trypsin inhibitor on inflammatory cytokines and organ function in patients with cardiopulmonary bypass. Eur Rev Med Pharmacol Sci. 2017;21(9):2220-5.

36. Li D, Ji H, Zhao B, Xu C, Xia W, Han L, Yu D, Ju Y, Jin C. Therapeutic effect of ulinastatin on pulmonary fibrosis via downregulation of TGFbeta1, TNFalpha and NFkappaB. Mol Med Rep. 2018;17(1):1717-23.

37. Liu H, Duan C, Li X, Wei G, Yang X, Jiao L, Wei X, Yang F. The changes of NSE, COX-2 in brain and the therapeutic effect of Ulinastatin after paraquat poisoning., Ninth Academic Conference of the Committee of Critical Care Medicine of Shandong Society of Pathophysiology and Fourth Academic Conference of 
Emergency Medical Doctors Branch of Shandong Medical Association, Jining Shandong, 2013, 19-21. (article in chinese).

\section{Figures}
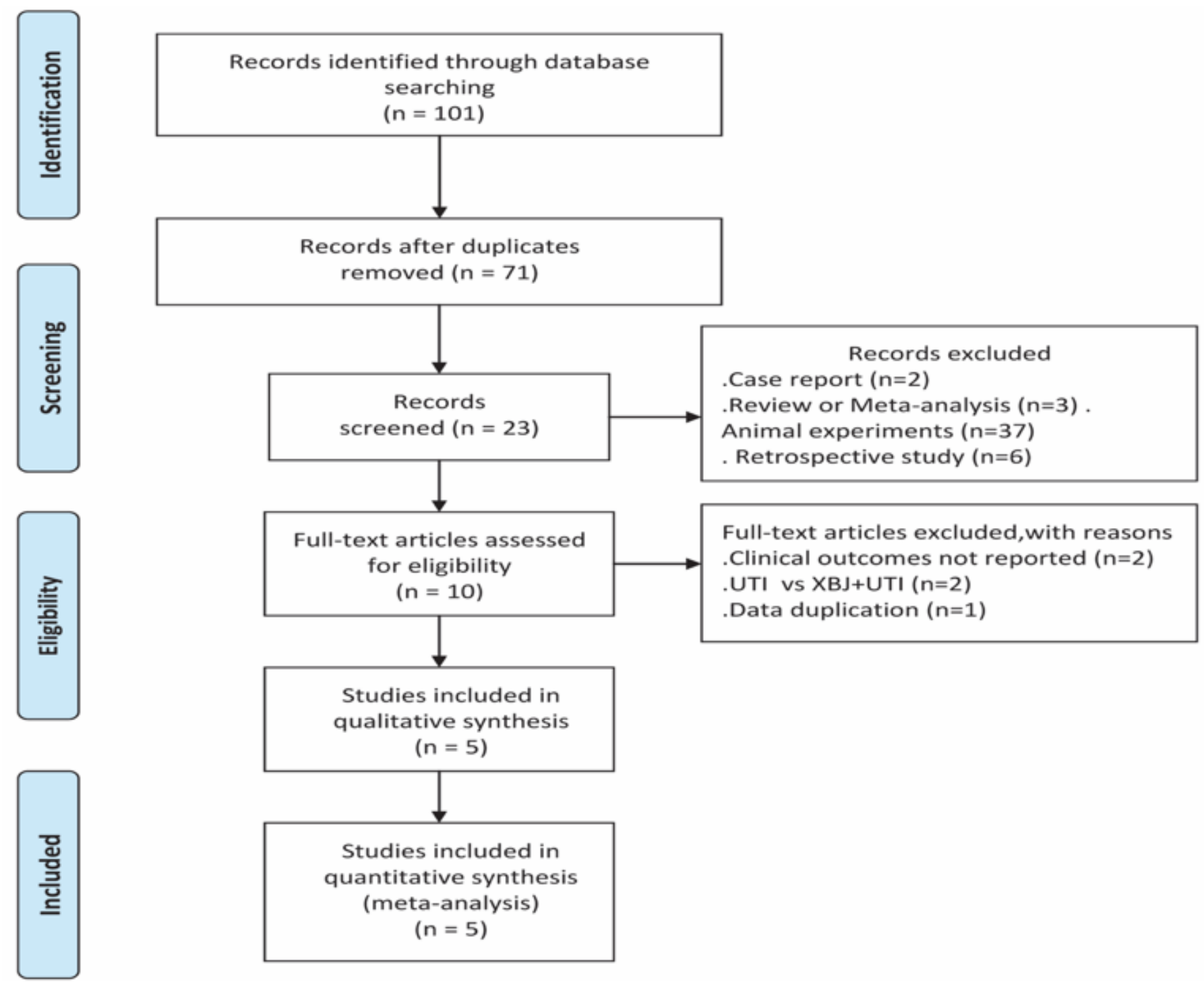
Full-text articles assessed for eligibility $(n=10)$
Full-text articles excluded, with reasons .Clinical outcomes not reported $(n=2)$ .UTI vs XBJ+UTI $(n=2)$
. Data duplication $(n=1)$

\section{Figure 1}

PRISMA flow diagram of the literature search and study selection 


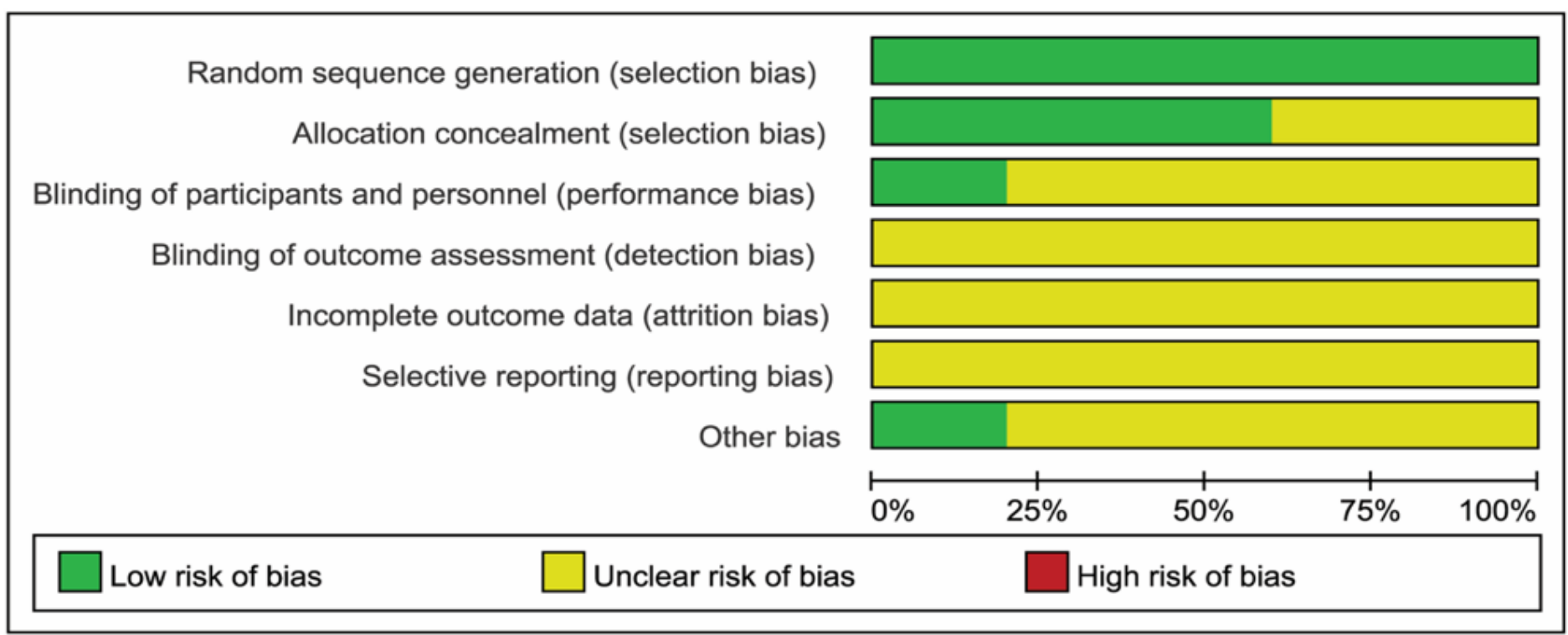

Figure 2

Risk of bias graph

Study

ID
Events, Events, \% RR $(95 \% \mathrm{Cl}) \quad$ XBJ+UTI Control Weight

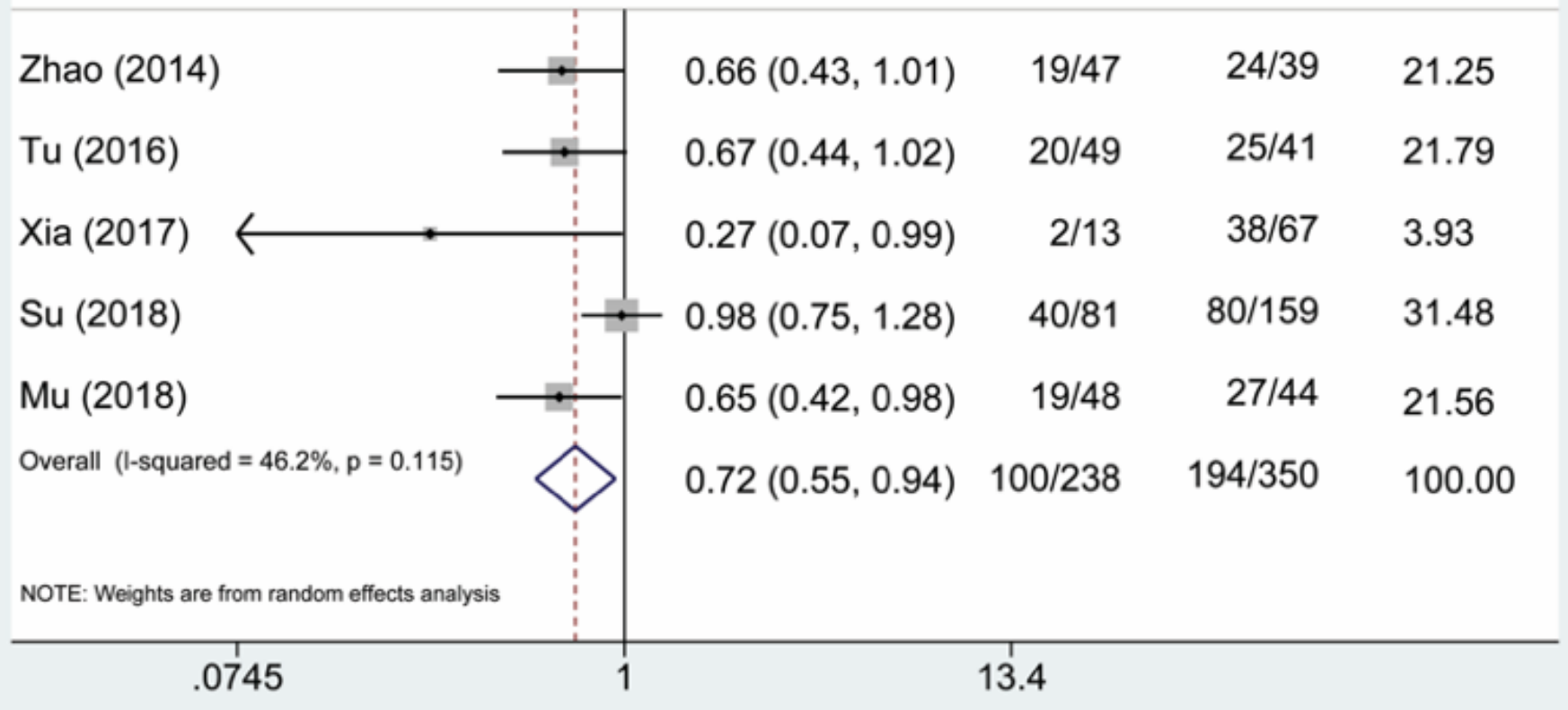

Figure 3 
Study

ID

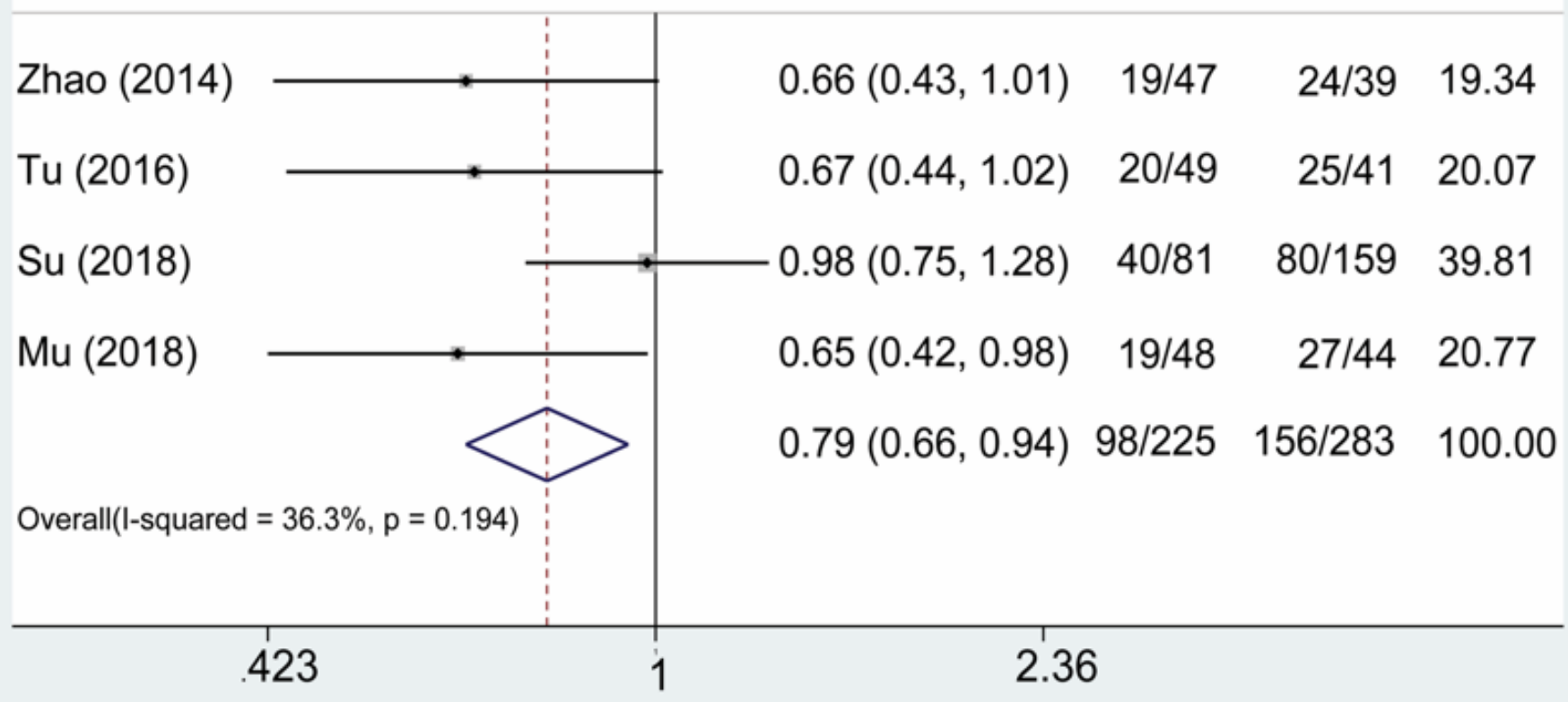

Figure 4

Forest plot comparing the mortality rate between the XBJ+UTI and control groups (after excluding Xia[14]'s study) 
Study

ID D

Events, Events, $\%$ RR $(95 \% \mathrm{Cl}) \quad$ XBJ+UTI Control Weight

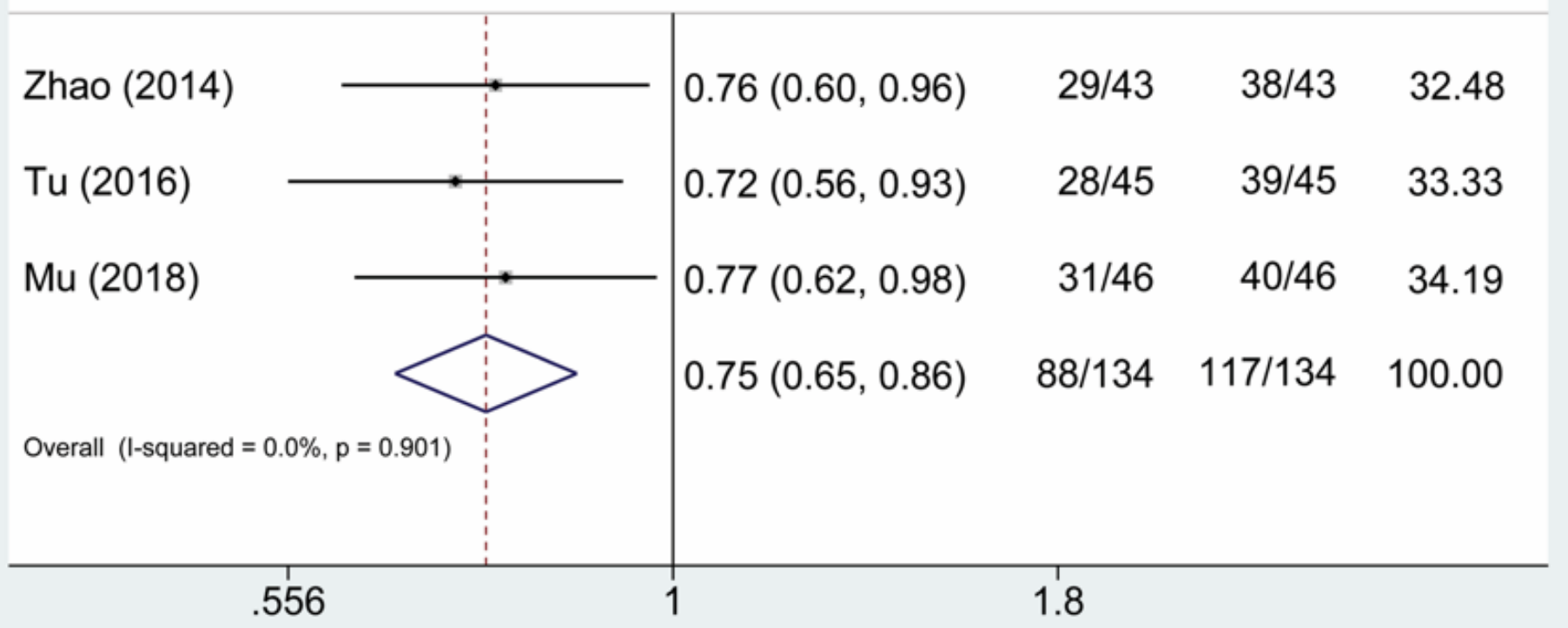

Figure 5

Forest plot comparing MODS incidence between the XBJ+UTI and control groups 
Study

ID
Events, Events, \% RR $(95 \% \mathrm{Cl}) \quad$ XBJ+UTI Control Weight

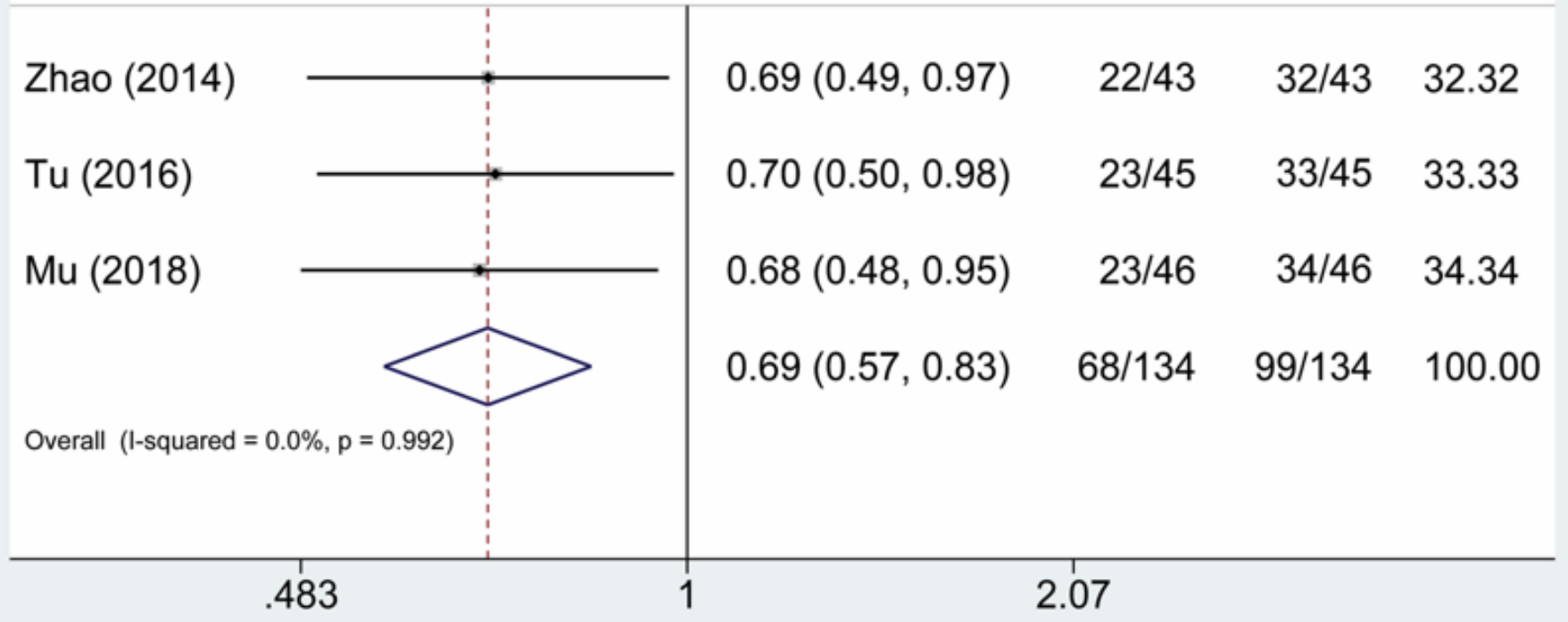

Figure 6

Forest plot comparing PF incidence between the XBJ+UTI and control groups

\section{Supplementary Files}

This is a list of supplementary files associated with this preprint. Click to download.

- Supplementary.SearchStrategy.docx 